\title{
ESTIMASI PENGUKURAN LAJU ALIRAN SIRKULASI ALAM PADA SIMULASI SISTEM PENDINGIN PASIF REAKTOR NUKLIR PRE-FASSIP 02
}

\author{
TRY HUTOMO PUTRA ${ }^{1 *}$, INTAN FARWATI ${ }^{1}$, ROSALDI PRATAMA $^{1}$, CUKUP MULYANA $^{1}$, \\ MULYA JUARSA ${ }^{2}$ \\ ${ }^{1}$ Departemen Fisika Fakultas MIPA Universitas Padjadjaran, \\ Jl. Raya Bandung-Sumedang Km 21,Jatinangor 45363
}

${ }^{2}$ Pusat Teknologi Keselamatan Reaktor Nuklir, Badan Tenaga Nuklir Nasional (BATAN), Gedung 80, Kawan Puspitek, Setu, Tangerang Selatan 15310, Jawa Barat

*email : try15001@mail.unpad.com

\begin{abstract}
Abstrak. Padamnya pendingin aktif di reaktor nukir Fukushima Daiichi menyebabkan sisa panas reaksi fisi berantai tak kunjung didinginkan. Tsunami setinggi 13 m merendam generator listrik cadangan saat terjadi Station Black Out. Akibatnya terjadi kerusakan pada teras reaktor hingga menimbulkan ledakan gas hidrogen yang dapat menyebabkan radiasi radioaktif tercemar kelingkungan. Pengembangan sistem pendingin pasif untuk menggantikan sistem aktif sangat diperlukan. Dengan prinsip kerja natural circulation, air yang panas akan menuju ke daerah yang dingin karena adanya bouyancy (Gaya Apung). Maka dibuat fasilitas simulasi Untai Pre-FASSIP 02 untuk mensimulasikan kejadian pemanasan reaktor dan pendinginan berskala medium. Laju aliran merupakan hal yang sangat penting untuk mendinginkan. Hasil eksperimen menunjukan kecepatan laju aliran pada Pre-FASSIP 02 paling tinggi adalah $0.062 \mathrm{~m} / \mathrm{s}$ dan yang paling rendah adalah $0.026 \mathrm{~m} / \mathrm{s}$.
\end{abstract}

Kata kunci: sistem pendingin pasif, Pre-FASSIP 02, Laju Aliran, sirkulasi alam

\begin{abstract}
Tsunami with $13 \mathrm{~m}$ height flooded the low-lying rooms in which the emergency generators were housed in Fukushima Daiichi disaster. The emergency generators supposed to run cooling pump. The consequence, fuel rods became hot enough to melt because of fission reaction from nuclear fuel still produced decay heat. Passive Cooling System (PCS) research and development is an important thing to help cooling the hot reactor because of decay heat from fission reaction while Active Cooling System is down. Pre-FASSIP 02 has a purpose to simulate the incident with medium scale. The purpouse of this experiment is to estimate velocity flow of natural circulation in PreFASSIP 02. Experiment shows that the fastest velocity flow is $0.062 \mathrm{~m} / \mathrm{s}$ and the slowest is $0.026 \mathrm{~m} / \mathrm{s}$.
\end{abstract}

Keywords: passive cooling system, Pre-FASSIP 02, velocity flow, natural circulation

\section{Pendahuluan}

Pembangunan PLTN di Indonesia semakin sulit untuk diterima banyak orang. Padahal telah dilakukan penelitian oleh BATAN (Badan Tenaga Nuklir Nasional) bahwa di Pulau Jawa tepatnya di Pantai Utara Kabupaten Batang menunjukan kelayakan sebagai tapak PLTN dan sudah sesuai regulasi untuk pembangunan PLTN yang dikeluarkan Badan Tenaga Atom Internasional [1]. Salah satu sebab masyarakat tidak menerimanya adalah kecelakaan reaktor Fukushima Daichi pada tahun 2011 yang menjadi trauma berkelanjutan. Gempa dengan kekuatan 9 Skala Ritcher itu mampu membawa tsunami dengan ketinggian 15 meter. Hal ini 
menyebabkan sistem pendingin aktif (pompa sirkulasi) pada PLTN mengalami tidak berfungsi karena padam listrik dan genset cadangan terendam oleh tsunami. Keadaan ini membuat reaktor tidak kunjung mendingin sehingga teras reaktor meleleh diiringi dengan ledakan gas hidrogen yang timbul dari reaksi air dengan pelapis atau pelindung bahan bakar yang gosong [2].

Pengembangan teknologi sistem pendingin pasif (passive cooling system) akan sangat dibutuhkan agar dapat membantu mendinginkan reaktor yang panas karena sisa peluruhan (decay heat) ketika sistem pendingin aktif mati. Sistem pendingin pasif adalah sistem pendingin yang dapat bekerja tanpa menggunakan energi listrik. Penggunaan sistem pendingin pasif akan meningkatkan keamanan reaktor nuklir dan mencegah tercemarnya radiasi ke lingkungan $[3,4]$.

Penelitian tentang pendingin pasif untuk reaktor nuklir sudah banyak dilakukan oleh banyak ilmuan dengan menggunakan simulasi dan eksperimen. Salah satunya adalah penyelidikan penggunaan heat pipe untuk menghilangkan pemanasan pada kolam bahan bakar nuklir secara simulasi dan eksperimen. Hasilnya menunjukan bahwa heat pipe memiliki kapabilitas untuk menjadi sistem pendingin pasif [5].

Pada penelitian yang dilakukan oleh Juarsa et al. 2018 telah menunjukan adanya sirkulasi alam pada FASSIP-02 yaitu sistem pendingin pasif dengan skala besar. Dengan gaya bouyancy dan mengandalkan gaya gravitasi menunjukan adanya pendinginan [6]. Sirkulasi alam terjadi dengan indikator kecepatan aliran mengarah ke tangki pendingin pada sistem dari tangki pemanas karena gaya bouyancy.

Untuk mempelajari lebih lanjut tentang fenomena sirkulasi alam dan pengembangan fitur keselamatan reaktor, telah dilakukan penelitian terkait sistem pendingin pasif dengan fasilitas simulasi skala medium yang disebut Pre-FASSIP 02. Pre-FASSIP 02 telah dibangun di Pusat Teknologi dan Keselamatan Reaktor Nuklir (PTKRN) BATAN. Fasilitas simulasi ini dapat memperlihatkan sifat aliran sirkulasi alam akibat kenaikan temperatur di pemanas dan turunnya densitas air. Fenomena tersebut dapat disebut gaya apung (bouyancy) dan ketika air masuk ke bagian pendingin mengalami pendinginan sehingga densitas air meningkat kembali lalu jatuh karena gaya gravitasi.

Oleh karena itu penting sekali mengetahui kecepatan aliran sirkulasi alam selama kenaikan temperatur pada Untai Pre-FASSIP 02 untuk menilai seberapa baik sistem pendingin pasif melakukan pendinginan selama sistem pendingin aktif padam.

\section{Metode Penelitian}

Untai Pre-FASSIP-02 dirancang untuk melihat fenomena sirkulasi alam dalam skala kecil. Sirkulasi alam dimanfaatkan untuk mendinginkan sistem reaktor nuklir. Pendinginan bersifat pasif karena tidak memerlukan pompa sirkulasi. Pada Gambar 1. merupakan desain Untai Pre-FASSIP-02. Pre-FASSIP-02 adalah akronim dari Preliminary Fasilitas Simulasi Sistem Pasif unit 02.

Gambar 1. merupakan desain untai Pre-FASSIP 02 yang dirancang menggunakan software gambar 3D. Bahan yang digunakan untuk pemipaan adalah pyrex karena memiliki titik didih yang tinggi. Selain itu komponen yang paling penting adalah heater diumpamakan sebagai reaktor nuklir yang panas. Dan cooler tank sebagai pendingin. Kemudian penukar panas yang digunakan adalah tembaga, karena 
penukar panas yang sangat baik. Prosedur eksperimen dilakukan dengan 6 tahapan seperti ditujukan oleh Gambar 2.

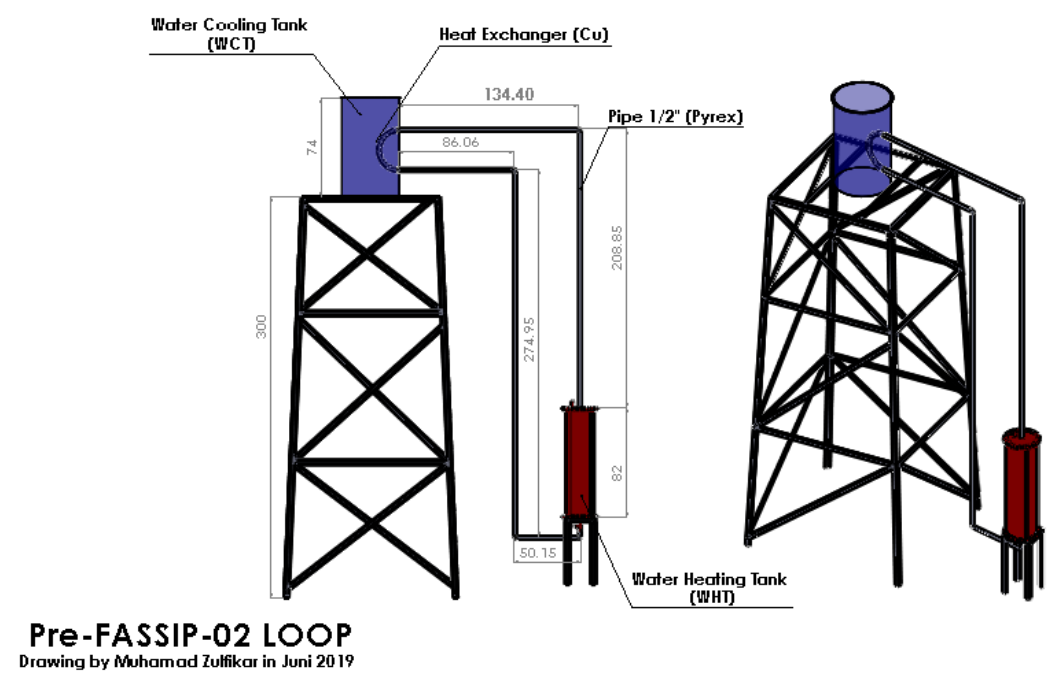

Gambar 1. Desain Untai Pre-FASSIP 02

Tabel 1. Bahan dan Geometri dari Untai Pre-FASSIP 02

\begin{tabular}{|c|c|c|}
\hline Barang & Geometri & Ukuran/Bahan \\
\hline Water Cooler Tank & Silinder & $\begin{array}{l}\text { Dia. } 44 \mathrm{~cm} \text {, tinggi } 74 \mathrm{~cm} \\
\text { (Plastik polyethylene) }\end{array}$ \\
\hline Water Heating Tank & Silinder & $\begin{array}{l}\text { Dia. } 22 \mathrm{~cm} \text {, tinggi } 81 \mathrm{~cm} \\
\text { (Akrilik) }\end{array}$ \\
\hline Pipa & Silinder & Dia. $1 / 2$ inch, Pyrex \\
\hline Heat Exchanger & Silinder & Dia. 1/2 Inch, (Tembaga) \\
\hline Pemanas & - & $\mathrm{P}=1 \mathrm{~kW}$ \\
\hline Perbedaan ketinggian $(\mathrm{H})$ & - & $180 \mathrm{~cm}$ \\
\hline $\begin{array}{l}\text { Koefisien Loss Keseluruhan } \\
(\mathrm{K})\end{array}$ & - & 7.6 \\
\hline Panjang Pipa Keseluruhan (L) & - & $735 \mathrm{~cm}$ \\
\hline
\end{tabular}

Setelah desain dan konstruksi selesai, kemudian Pre-FASSIP 02 diisi air hingga tidak ada kebocoran dan udara terjebak didalam sistem. Heater dihidupkan dengan variasi panas $60^{\circ} \mathrm{C}, 70^{\circ} \mathrm{C}$ dan $80^{\circ} \mathrm{C}$ lalu distabilkan selama 1 jam, pengontrolan kestabilan temperatur diatur pada software LABVIEW dan menggunakan hardware Solid-State Relay.

Instrumentasi pengukuran merupakan hal yang sangat penting untuk merekam data perubahan temperatur yang terjadi pada sistem. Software LABVIEW sangat cocok digunakan sebagai antarmuka dengan pengguna dan berkomunikasi dengan hardware NI DAQ. 12 Termokopel dipasang pada setiap bagian yang penting untuk direkam perubahan temperaturnya. Gambar 3. Merupakan antarmuka software LABVIEW yang dibuat. 


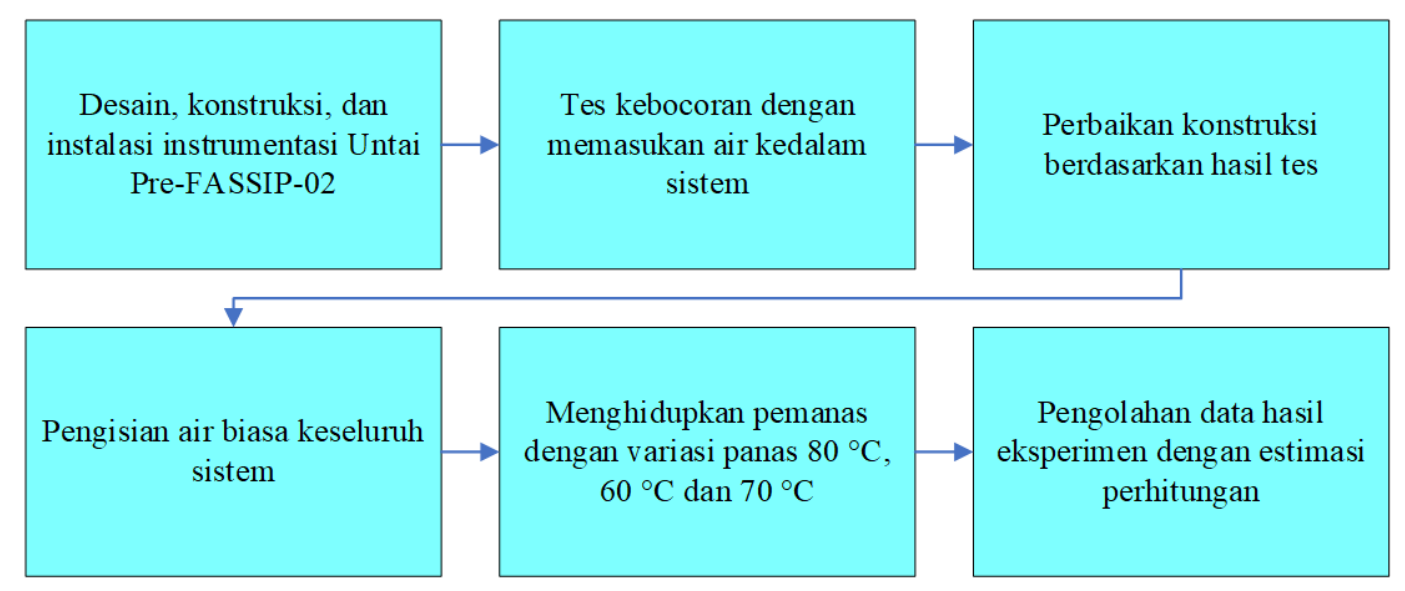

Gambar 2. Tahapan Penelitian yang Dilakukan

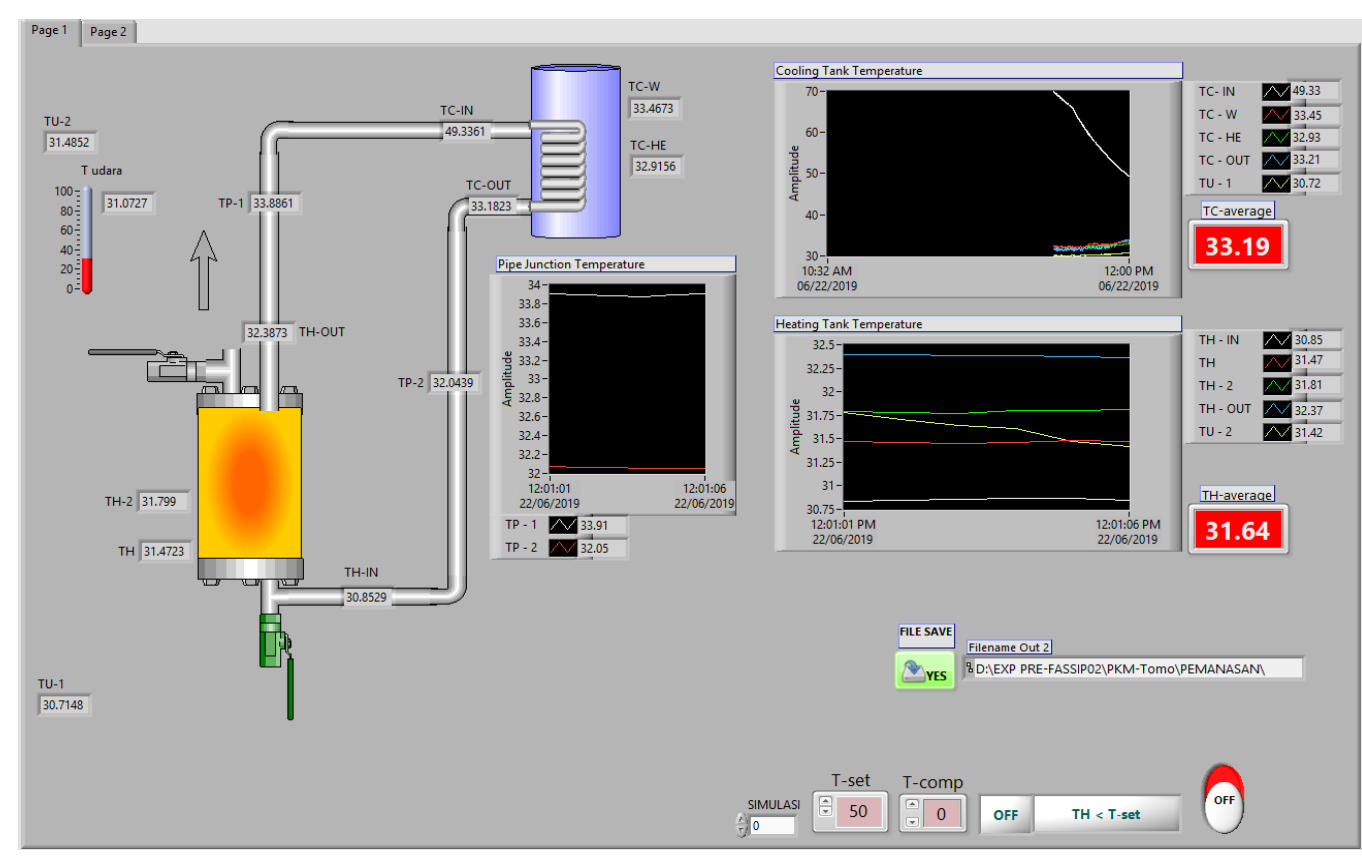

Gambar 3. Antarmuka Software LABVIEW Dilengkapi dengan Pengontrol Temperatur

\section{Hasil dan Pembahasan}

Untuk menentukan kecepatan aliran digunakan persamaan yang telah diteliti sebelumnya oleh Juarsa et. al, 2018. Persamaan yang digunakan adalah persamaan termohidraulik dengan melibatkan fungsi dinamika fluida terhadap temperatur. Persamaan ditujukan oleh Persamaan (1).

$$
v=\frac{-64 \mu L_{-}^{ \pm} \sqrt{64 \mu L^{2}+8 g H K \bar{\rho}\left(\rho_{c}-\rho_{h}\right) D^{4}}}{2 \bar{\rho} K D^{2}}
$$

Fungsi massa jenis terhadap temperatur didapat $\rho(T)=1004.789042-$ $0.046283(1.8 T+32)-7.9738 \times 10^{-4}(1.8 T+32)^{2}$ dan viskositas dinamis dari air $\mu(T)=\exp \left[\frac{(A+C T)}{\left(1+B T+D T^{3}\right.}\right]$. Dengan melibatkan nilai geometris pada bab 
sebelumnya seperti perbedaan ketinggian heater dan cooler $(\mathrm{H})$, panjang total pemipaan (L), diameter pipa (D), dan koefisien loss (K), didapatkan kecepatan aliran untuk masing - masing pengaturan temperatur $80^{\circ} \mathrm{C}, 70^{\circ} \mathrm{C}$ dan $60^{\circ} \mathrm{C}$. Nilai kecepatan terhadap waktu dapat dilihat pada Gambar 4.

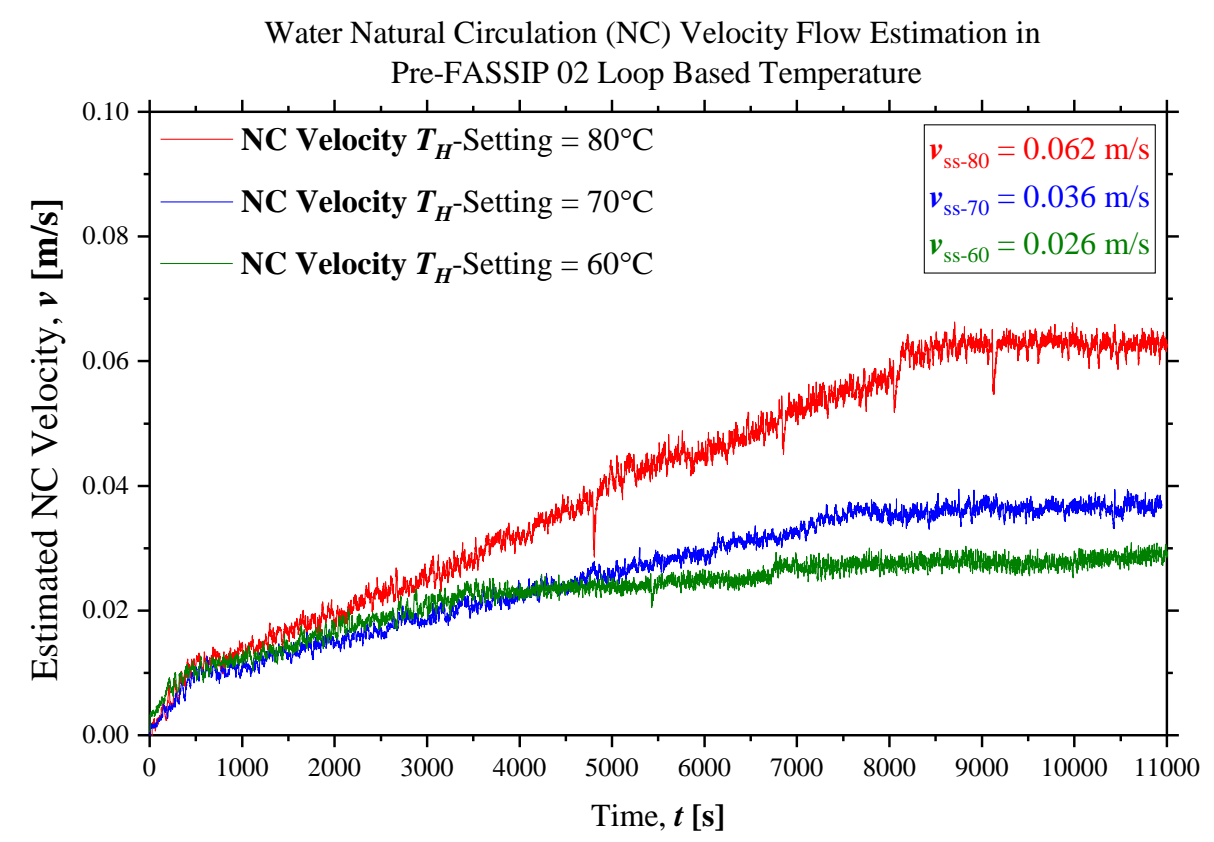

Gambar 4. Grafik Kecepatan Aliran Sirkulasi Alam Pada Pre-FASSIP 02

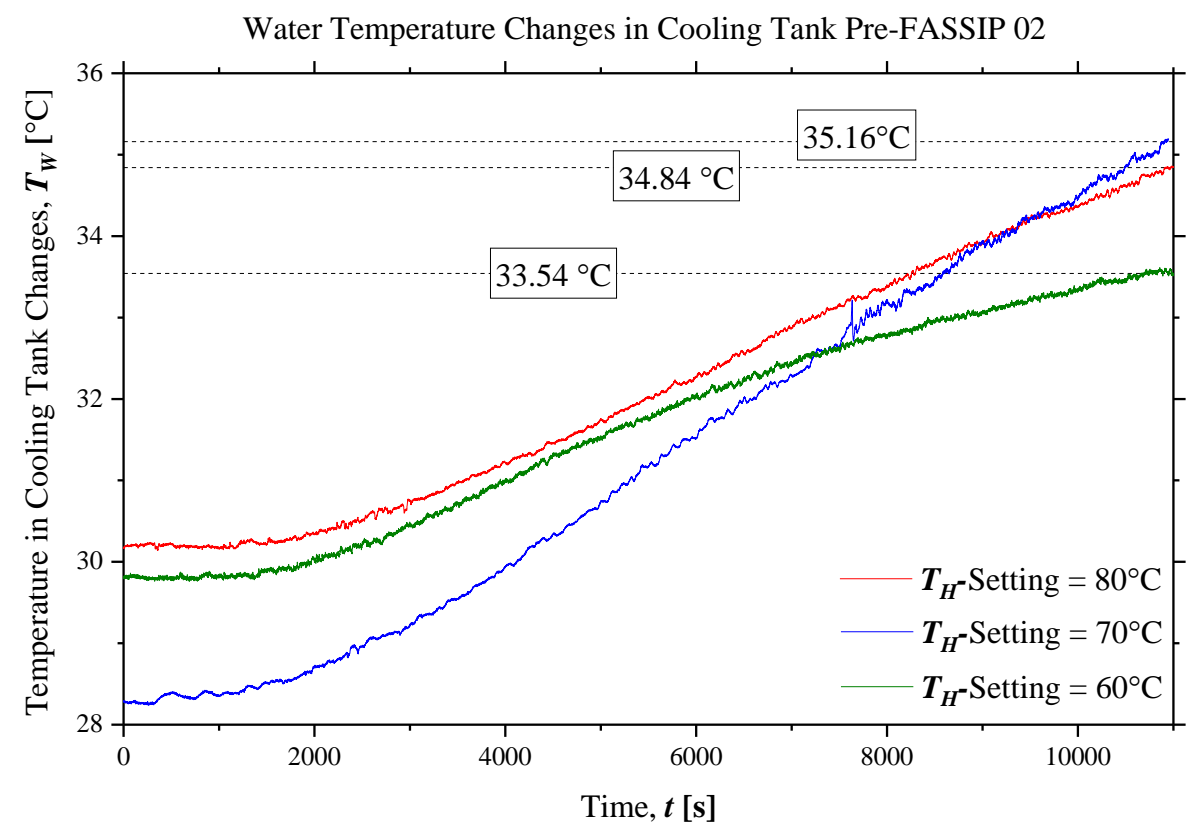

Gambar 5. Perubahan temperatur air pada cooler

Terlihat pada Gambar 4. Kecepatan aliran menaik seiring kenaikan waktu. Artinya bahwa ketika kenaikan waktu itu beriringan dengan pemanasan pada heater. Kenaikan kecepatan ini bersamaan dengan kenaikan temperatur pula. Semakin tinggi temperatur maka semakin cepat aliran sirkulasi alam. Penurunan massa jenis 
air terjadi hingga air menaik keatas ditandai dengan kecepatan. Seluruh pengaturan temperatur diatur hingga 11000 detik. Untuk penjelasan adanya pertukaran panas dapat dilihat pada Gambar 5.

Gambar 5. Menjelaskan kenaikan temperatur pada cooler seiring berjalannya waktu dan kenaikan temperatur di pemanas. Kenaikan temperatur pada cooler ini menjelaskan adanya pertukaran panas yang dilakukan oleh Heat Exchanger yang berbahan tembaga. Tangki pendingin mendapatkan panas paling besar adalah hingga $35.16^{\circ} \mathrm{C}$.

\section{Kesimpulan}

Berdasarkan kenaikan temperatur yang diatur dari $60^{\circ} \mathrm{C}, 70^{\circ} \mathrm{C}$ dan $80^{\circ} \mathrm{C}$ pada heater. Dapat disimpulkan bahwa laju aliran paling tinggi pada Pre-FASSIP 02 dengan geometri $\mathrm{H}=1.8 \mathrm{~m}, \mathrm{~L}=7.35 \mathrm{~m}, \mathrm{D}=0,0127 \mathrm{~m}$ adalah $0.062 \mathrm{~m} / \mathrm{s}$ dengan pengaturan temperatur $80^{\circ} \mathrm{C}$. Sedangkan untuk laju aliran yang paling rendah adalah $0.026 \mathrm{~m} / \mathrm{s}$ dengan pengaturan temperatur $60^{\circ} \mathrm{C}$.

\section{Ucapan Terima Kasih}

Penulis mengucapkan terimakasih kepada anggaran KEMENRISTEKDIKTI Program INSINAS Riset Pratama Kemitraan antara PTKRN BATAN-FTUI dengan nomor kontrak 02/INS-2/PPK/E/E4/2017 dan juga Program Kreativitas Mahasiswa 2018 oleh KEMENRISTEKDIKTI.

\section{Daftar Pustaka}

1. H., C. M., K., S. S. dan J. L. D. (2000) "SMART behavior under overpressurizing accident condition," Nuclear Engineering and Design, 199(1), hal. 187-196.

2. I. Hamzah dan I.G. Sukadana, Pantai utara kabupaten batang sebagai alternatif calon tapak pltn, (2010) 56-65.

3. IAEA (2016) Fukushima Nuclear Accident. Tersedia pada: https://www.iaea.org/newscenter/focus/fukushima (Diakses: 30 Oktober 2018).

4. M. Juarsa et al. Estimation of natural circulation flow based on temperature in the FASSIP-02 large-scale test loop facility Estimation of natural circulation flow based on temperature in the FASSIP-02 large-scale test loop facility, in IOP Conf. Series: Earth and Environmental Science. IOP Publishing, (2018) 0-7.

5. M. H. Kusuma et. al, Investigation of the Thermal Performance of a Vertical Two-Phase Closed Thermosyphon as a Passive Cooling System for a Nuclear Reactor Spent Fuel Storage Pool, Nuclear Engineering and Technology, Vol. 49 No. 3 (2017) 476-483.

6. H. S. Park et. al, Contribution of thermal-hydraulic validation tests to the standard design approval of SMART Nuclear Engineering and Technology (2017). 